\title{
Nutrition literacy is associated with income and place of residence but not with diet behavior and food security in the Palestinian society
}

\author{
Nihal Natour, Mariam AL-Tell and Osama Ikhdour
}

\begin{abstract}
Introduction: Palestinian society is going through health transition that is associated with increase in chronic diseases due to poor dietary habits so adequate integration of nutrition information is important.

Aims: The aim of this study is to find the association between nutrition literacy and diet behavior among a group of Palestinian participants.

Methods: A sample of 101 Palestinian participants were recruited to participate in the study. An online survey was used to collect study data. Newest Vital Sign quiz was used to collect information on nutrition literacy and Short Format of the Diet Health and Knowledge Survey (SFDHKS) was used to collect information on diet behavior and USDA food security questionnaire was used to collect data on food security. Data was analyzed utilizing SPSS 21.

Results: This study included 101 participants, mean age 22.7 y $\pm 8.7 \mathrm{y}$, mainly females (females were $83.2 \%$ and males were $16.8 \%$ ). $5.7 \%$ of the study participants were obese, $13.8 \%$ overweight and $10.3 \%$ were underweight. The prevalence of adequate nutrition literacy was 29\%. There was minimal association between diet behavior and nutrition literacy, food security and BMI categories, but significant association with income and living in city relative to village $(p<0.05)$. Only 11 participants had some form of food insecurity.
\end{abstract}

Conclusion: There is low prevalence of adequate nutrition literacy. Nutrition literacy depends on social and economic aspects but further research is need to understand its relationship to diet behavior.

Keywords: Diet, Nutrition literacy, Obesity, Food security

\section{Introduction}

Diet is a major risk factor for chronic diseases including type 2 diabetes mellitus, cardiovascular diseases and cancer. Chronic diseases rates have increased globally [1]. Poor dietary habits account for $16 \%$ of all-cause mortality in USA adults according to data from National Health and Nutrition Examination Survey (NHANES 1999-2010) and healthy eating index of 2015 [2]. Diet

\footnotetext{
* Correspondence: n.natour@najah.edu

Department of Public Health, School of Medicine, An-Najah University, Nablus, Palestine
}

related problems including obesity account for increased health cost and lower quality of life [3, 4]. Dietary habits correlate with socioeconomic factors in different sections of the society, data from NHANES indicates that healthy eating index was 4 times higher for adults with high versus low education and 2 times higher for food secure versus food insecure [5].

Efforts to improve dietary habits in Palestine could be accomplished by enhancing nutrition knowledge. Food literacy, nutrition literacy and health literacy are concepts that reflect general knowledge about health and

(c) The Author(s). 2021 Open Access This article is licensed under a Creative Commons Attribution 4.0 International License, which permits use, sharing, adaptation, distribution and reproduction in any medium or format, as long as you give appropriate credit to the original author(s) and the source, provide a link to the Creative Commons licence, and indicate if changes were made. The images or other third party material in this article are included in the article's Creative Commons licence, unless indicated otherwise in a credit line to the material. If material is not included in the article's Creative Commons licence and your intended use is not permitted by statutory regulation or exceeds the permitted use, you will need to obtain permission directly from the copyright holder. To view a copy of this licence, visit http://creativecommons.org/licenses/by/4.0/ The Creative Commons Public Domain Dedication waiver (http://creativecommons.org/publicdomain/zero/1.0/) applies to the data made available in this article, unless otherwise stated in a credit line to the data. 
nutrition. Food literacy can be defined as the ability to understand, use, analyze and communicate nutrition information [6], whereas nutrition literacy means the ability of a person to seek, understand and apply basic nutrition information [7]. In one study among 386 American adults higher nutrition literacy significantly correlated with adherence to prudent diet $(P<0.001$, $\beta=0.36)$, Mediterranean diet $((P=0.02, \beta=0.12)$ and was inversely related to adherence to westernized diet $(P=0.003, \beta=-0.13)$ even after adjustment for covariates including age, BMI and gender [8]. On the other hand, poorer health literacy as measured by NVS was associated with increase in BMI $((r=-0.12, p=.027)$, increase in age $((r=-0.26, p<.001)$ and higher NVS measured literacy was more common in higher income and education [9]. Improving individuals' access to information and their ability to use them is considered effective involvement of adults in managing their health [10]. Improving nutrition literacy could lead to better healthful diet decisions and can be achieved by many tools such as food labels and printed brochures and material to deliver nutrition information [11]. Literacy itself which is defined as "an individual's ability to read, write, and speak in English and compute and solve problems at levels of proficiency necessary to function on the job and in society, to achieve one's goals, and to develop one's knowledge and potential." Is important to use and apply distributed nutrition information [12].

The Palestinian society is in health transition associated with open food market with different countries [13]. In a recent study by a group of Palestinian researchers the prevalence of being overweight or obese is $65.3 \%$ and metabolic syndrome is 33\% [14]. with current adoption of western lifestyle near crowded urban centers changes to generation dietary habits is prevalent in many countries including Palestine [15]. Having adequate nutrition knowledge could hinder the shift in obesity and chronic diseases epidemic in Palestine. The aim of this paper: 1) To study the level of nutrition literacy among a group of Palestinians using NVS 2) To study the relationship between dietary habits and nutrition literacy. 3 ) To study the differences in dietary habits according to BMI categories and food security categories.

\section{Methods}

A cross-sectional design was used to evaluate nutrition literacy, food security and its association with dietary habits. Palestinians older than $18 \mathrm{y}$ were recruited through an electronic data collection tool which was distributed through different social media methods that included facebook and professional, social and student facebook groups, in addition to the university website. The population consisted of all Palestinians living in the West Bank, Gaza, and in Israel. A convenient sampling method was adopted. sample size of $n=101$ adults participated in this study. The data collection tool was adopted based on a Literature review [16, 17]. Information on age, weight, height,diet, use of food label, items of food label used,gender, education, income were obtained. The Newest Vital Sign (NVS) of 5 items was used to assess nutrition literacy [18]. NVS assessed participants to understand and calculate basic nutrition information using two nutrition fact labels obtained from Palestinian common products [18]. Each correct answer was given one point and a total score ranged from 0 to 5 , and categorized as following $0-1$ this indicated lack of nutrition literacy, 2-3 indicated possibility of limited nutrition literacy and 4-5 indicated adequate nutrition literacy. NVS was validated before [18]. A translated to Arabic version was used in our study which was reviewed by expertsThe food labels that were presented to participants were 1) a food label of commonly purchased biscuits that had information (in arabic and English) pertaining to serving size, total calories, percent daily value and grams per serving of total fat, saturated fat, cholesterol, transfat, carbohydrate including total sugars, added sugars, dietary fibers and proteins. 2) a food label from bagel salty snack that shows a list of ingredients in arabic in that food. Both pictures are attached as supplementary material.

Arabic translated version of dietary habits was used and consisted of nineteen questions from the Short Format of the Diet Health and Knowledge Survey(SFDHKS) [19] was used to measure food label use and diet behavior the translated tool was reviewed by experts. A short form of USDA food security scale was used and we used questions $\mathrm{AD} 1$ and $\mathrm{AD} 1 \mathrm{a}$ after converting the answers to likert scale numbers to classify food security into food secure and insecure [20]..

\section{Statistics}

The ordinal data for the answers of SFDHKS was converted into Likert scale numbers. Proportions of various sociodemographic, nutrition literacy, obesity and food security were calculated. Normality of continuous variables was calculated. Non-parametric test was used to compare SFDHKS, BMI and age between food secure and insecure and medians and range were reported. One way ANOVA was used to compare food behavior variables across food literacy groups and BMI categories. Chi-square was used to study association between categorical variables.

\section{Results}

This study included 101 participants, mean age $22.7 \mathrm{y} \pm$ $8.7 \mathrm{y}$. Relatively there was low prevalence of obesity, but higher prevalence of overweight and underweight participants (Fig. 1). NVS consisted of 5 questions; the first 


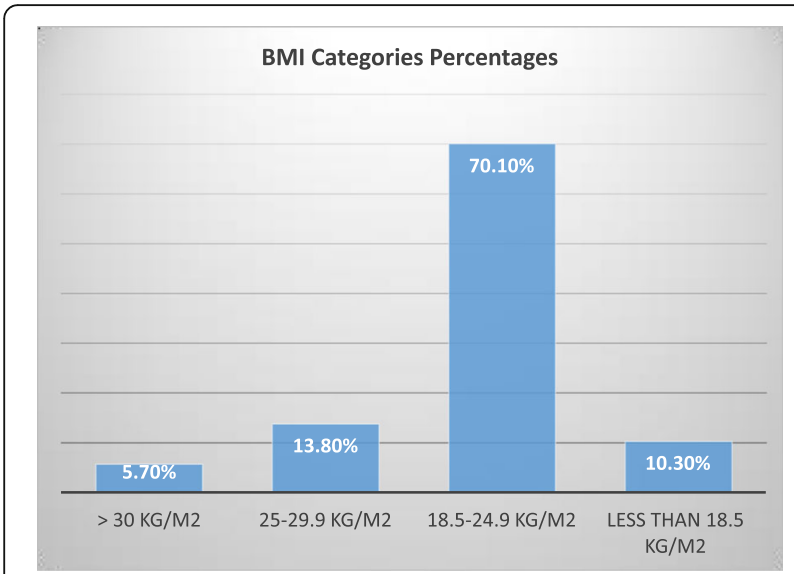

Fig. 1 Percentages of Various BMI Categories. Chi-Square $=10.9, \mathrm{p}$-value $=0.027$

question asked the study group about the total calories in the whole package and for this question $66 \%$ had correct answers,2) the second question was if you were to take $60 \mathrm{~g}$ of carbohydrate how much of the product you will consume and for this $35 \%$ answered correctly 3) the third question what is the percent of total needed calories does one serving of this product provides based on $2000 \mathrm{kcal}$ need, and for this only $35 \%$ answered this correctly. 4) The participants were asked if they would consume the product if they have allergy for soy and barely and for this 95\% answered correctly and fifth question was if you have allergy why will you stop eating this product and for this $55 \%$ answered correctly. Table 1 describes study main variables. The study group were mostly females, the prevalence of adequate literacy was slightly more than quarter of the study participants. Most of the study participants reported a household income of 3000-5000 shikel and having or doing bachelors degree. Only 11 participants reported some form of food insecurity. Also, mean of total nutrition literacy score was compared across study variables' categories; Females, group with higher income, food label user and group who consumed low calorie products and looked on health benefits on food label had higher food literacy score (Table 1). Table 2 describes comparison of dietary habits between food literacy groups. Participants with adequate literacy reported lower use of high fat cheese, fried chicken and higher removal of chicken skin. Other variables were not significantly different between nutrition literacy. Table 3 show comparison of study variables between food secure and insecure adults, food secure were more likely to use mayonnaise and cheese as addition to their food and less likely to remove the skin of the chicken. Table 4 describe differences of study diet variables between BMI categories. Use of low fat milk was least common among adults with normal BMI.
Underweight participants did not care to consume low fat and low calorie products.

Nutrition literacy was not different according BMI, food label, food security and gender categories. In multiple regression model (Table 5), being from a village significantly reduced total nutrition literacy score, whereas food security was strongly but not significantly related to nutrition literacy score.

\section{Discussion}

This study involved participants from the Palestinian society from different age groups through online recruitment, however females and younger adults were more willing to participate in the study. In our study $29 \%$ of the study group had adequate nutrition literacy which is slightly lower than what was reported in other groups [17]. Our study group were low to middle income group, the group with higher income had better literacy compared to other groups. Studies and public campaigns to improve nutrition knowledge among the general Palestinian society and skills to read food labels and perform simple nutrition calculations are limited. We have performed a study on food label use among Palestinian group and found that although the use of food labels among Palestinian society is very common, they only seeked information on crude values of calories, sugar and fat without looking into important information such as sodium content and types of harmful lipids in food products [23]. Nutrition education in Palestinian society is imperative and should be supported with appropriate funding that direct resources on important tools such as raising awareness to nutrition comprehension skills among the various sectors of the society.

Similar to what others found, majority of study participants did not answer the calculation questions correctly. The first three question required document literacy and numeracy literacy skills but the other two did not require that. This is in accordance with what was found for a group of Americans which could indicate that numeracy represents a challenge for many [20]. Dietitian and nutritionists should perform more efforts in trying to simplify nutrition guidance which requires some numeracy skills by providing the client with more simplified information.

Income and whether the participant is from village or city were significantly related to nutrition literacy. Participants with higher income and from cities had higher nutrition literacy than participants from villages and lower income. Since most of our study participants were females this could reflectpatriarchy [24] than sociodemographic variables. Income gap and geographical locations of Palestinian villages could not justify discrepancies in terms of access to healthcare Many Palestinian villages are close to cities centers, and despite the fact 
Table 1 Distribution of participants' percentage according to their demographic data

\begin{tabular}{|c|c|c|}
\hline Variable & $\mathrm{N}(\%)$ & Mean \pm SD \\
\hline \multicolumn{3}{|l|}{ Newest Vital Sign } \\
\hline High Likelihood of Limited Health Literacy & 19/103 (18.4\%) & $0.8 \pm 0.4^{a}$ \\
\hline Possible Limited Health Literacy & $54 / 103(52 . .4 \%)$ & $2.5 \pm 0.5^{b}$ \\
\hline Adequate Health Literacy & $30 / 103(29.1 \%)$ & $4.4 \pm 0.5^{c}$ \\
\hline \multicolumn{3}{|l|}{ Gender } \\
\hline Male & 17/101 (16.8\%) & $2.3 \pm 0.95^{\mathrm{a}}$ \\
\hline Female & 84/101 (83.2.\%) & $3.0 \pm 1.1^{\mathrm{b}}$ \\
\hline \multicolumn{3}{|l|}{ Income } \\
\hline Less than 3000 Shikel & 22/99 (22.2\%) & $2.2 \pm 1.1^{\mathrm{a}}$ \\
\hline 3000-6000 Shikel & $44 / 99(44.4 \%)$ & $3.2 \pm 1.3^{b}$ \\
\hline More than 6000 Shikel & 33/99 (33.3\%) & $2.9 \pm 1.2^{\mathrm{ab}}$ \\
\hline \multicolumn{3}{|l|}{ Place } \\
\hline Refugee Camp & $3 / 100(3 \%)$ & $2.5 \pm 0.7$ \\
\hline City & $55 / 100(55 \%)$ & $2.7 \pm 1.2$ \\
\hline Village & $42 / 100(42 \%)$ & $3.1 \pm 1.4$ \\
\hline \multicolumn{3}{|l|}{ Education } \\
\hline High School or less & $7 / 101(7 \%)$ & $3.3 \pm 1.3$ \\
\hline College & 12/101 (11.9\%) & $2.5 \pm 1.2$ \\
\hline Bachelor & 78/101 (77.2\%) & $2.9 \pm 1.3$ \\
\hline Postgraduate education & $4 / 101(4 \%)$ & $2.3 \pm 1.9$ \\
\hline \multicolumn{3}{|l|}{ Label USE } \\
\hline \multicolumn{3}{|l|}{ Use of food Label } \\
\hline May be & $24 / 101(24 \%)$ & $2.9 \pm 1.1^{\mathrm{ab}}$ \\
\hline No & $33 / 101(33 \%)$ & $2.3 \pm 1.1^{\mathrm{a}}$ \\
\hline Yes & $44 / 101(43 \%)$ & $3.3 \pm 1.2^{b}$ \\
\hline \multicolumn{3}{|l|}{ Looking at food Label } \\
\hline May be & $16 / 98(16.3 \%) 42 / 98$ & $2.9 \pm 1.1^{\mathrm{ab}}$ \\
\hline No & $(42.9 \%)$ & $2.4 \pm 1.3^{\mathrm{a}}$ \\
\hline Yes & $40 / 98(40.8 \%)$ & $3.2 \pm 1.3^{b}$ \\
\hline \multicolumn{3}{|l|}{ Look at health claim on food label } \\
\hline May be & 13/99 (13.1\%) & $2.9 \pm 1.4$ \\
\hline No & $56 / 99(56.6 \%)$ & $2.8 \pm 1.2$ \\
\hline Yes & $30 / 99(30.3 \%)$ & $2.7 \pm 1.4$ \\
\hline \multicolumn{3}{|l|}{ Look at calories on the food label } \\
\hline May be & $25 / 101(24.8 \%)$ & $2.7 \pm 1.1^{\mathrm{ab}}$ \\
\hline No & $41 / 101(40.6 \%)$ & $2.5 \pm 1.4^{\mathrm{a}}$ \\
\hline Yes & $35 / 101(34.7 \%)$ & $3.2 \pm 1.3^{b}$ \\
\hline \multicolumn{3}{|l|}{ Look at serving size on food label } \\
\hline May be & $38 / 101(37.6 \%)$ & $2.4 \pm 1.0$ \\
\hline No & $31 / 101(30.7 \%)$ & $2.1 \pm 1.2$ \\
\hline Yes & $32 / 101(31.7 \%)$ & $2.4 \pm 1.0$ \\
\hline \multicolumn{3}{|l|}{ Look at health benefit on Label } \\
\hline May be & $35 / 101$ (34.7\%) & $2.8 \pm 1.1^{\mathrm{ab}}$ \\
\hline No & 39/101 (38.6\%) & $2.6 \pm 1.4^{\mathrm{a}}$ \\
\hline
\end{tabular}


Table 1 Distribution of participants' percentage according to their demographic data (Continued)

\begin{tabular}{|c|c|c|}
\hline Variable & N (\%) & Mean \pm SD \\
\hline Yes & $27 / 101(26.7 \%)$ & $3.4 \pm 1.2^{b}$ \\
\hline \multicolumn{3}{|l|}{ Food Security } \\
\hline Food Secure & $89 \%$ & $2.9 \pm 1.3$ \\
\hline Modest insecurity & $8 \%$ & $2.8 \pm 1.4$ \\
\hline Severe insecurity & 3. $\%$ & $2.5 \pm 0.7$ \\
\hline
\end{tabular}

This table presents subcategories percentages and also it present NVS total score mean \pm SD for each categories, differences between means was calaculated using ANOVA. Means with different letters are statistically significant

Palestinian cities have higher concentration of nutrition care services, reaching out to these centers is feasible with the strong transportation system in the West Bank [25].

Most of our study participants did not use food label, or used information on them on calories, health benefits of the product. Less than half of our study group did not use low fat or low calorie diet or even low fat milk products, despite the fact that $50 \%$ reported using low fat meat. The low use of food label could be related to the fact that participants do not understand them, whereas the low purchase of low calorie or low fat milk products could be related to the fact they are expensive and this study group were mostly from low to middle income category $[22,26]$.

This study indicated low association between health literacy and food behavior. People with adequate literacy were more likely to eat reduced fat meat and to avoid eating fried chicken. One possible conclusion from this finding is that even people with adequate health literacy are unable to understand nutrition messages sent by nutrition practitioners in the society. In a previous study
[27] under review, we found that participants from health field students were able to understand how to use MyPlate American application. However, they reported low efficiency in applying what they learn from this website on their practical life. This indicates that health care providers need to simplify nutrition by providing practical workshops with graphs and cooking skills to the participants who wish to change their diet style.

Income was a significant predictor of nutrition literacy as well as living place which could reflect the importance of socioeconomic status on nutrition literacy. Similar to this study, a study among Iranian adolescents showed that mother education, higher socioeconomic status were associated with higher nutrition knowledge scores [28]. This was further supported by other studies [29, 30]. On the other hand, similar to our study in multiple regression models there was no significant association between BMI and nutrition literacy score [28]. Studies on the association between BMI and nutrition literacy are inconsistent $[30,31]$ and may differ according to age and gender. Our study was more representative of young adults and females.

Table 2 Differences between the Food Literacy Groups in relation to the dietary variables by ANOVA/F test

\begin{tabular}{|c|c|c|c|c|}
\hline Variable & Limited Literacy $(\mathrm{N}=19)$ & Possible Limited Literacy $(\mathrm{N}=54)$ & Adequate Literacy $(\mathrm{N}=30)$ & $F, p$-value \\
\hline Age (y) & $23.0 \pm 4.0$ & $22.2 \pm 7.7$ & $22.8 \pm 9.6$ & $1.16,0.32$ \\
\hline $\mathrm{BMI}\left(\mathrm{Kg} / \mathrm{m}^{2}\right)$ & $22.7 \pm 4.0$ & $22.6 \pm 3.7$ & $22.1 \pm 4.3$ & $0.16,0.85$ \\
\hline Consumption of low-fat/low-calorie foods & $1.86 \pm 0.64$ & $2.20 \pm 0.89$ & $2.30 \pm 0.94$ & $1.24,0.30$ \\
\hline Eat lower fat lunch meats & $1.26 \pm 1.1$ & $2.1 \pm 1.3$ & $1.90 \pm 1.2$ & $2.56,0.08$ \\
\hline Drink skim or $1 \%$ milk & $1.5 \pm 1.3$ & $1.6 \pm 1.2$ & $1.4 \pm 1.4$ & $0.04,0.96$ \\
\hline Low fat cheese & $1.0 \pm 1.13$ & $1.69 \pm 1.1$ & $1.31 \pm 1.39$ & $2.26, .11$ \\
\hline Use low calorie dressing & $0.80 \pm 0.7$ & $1.54 \pm 1.22$ & $1.37 \pm 1.24$ & $2.36,0.10$ \\
\hline Eat fried Potatoes & $2.8 \pm 1.0$ & $2.40 \pm 1.2$ & $2.60 \pm 0.77$ & $0.92,0.40$ \\
\hline Frying veggi & $1.4 \pm 0.7$ & $1.5 \pm 1.1$ & $1.6 \pm 1.1$ & $0.09,0.9$ \\
\hline Adding cheese and mayonise & $1.7 \pm 0.8$ & $1.6 \pm 0.8$ & $1.7 \pm 0.8$ & $0.8,0.46$ \\
\hline Eat butter, bread, cake & $1.6 \pm 1.3$ & $1.8 \pm 1.0$ & $0.9 \pm 0.9$ & $2.9,0.07$ \\
\hline Avoid extra fat & $2.0 \pm 1.3$ & $2.5 \pm 1.2$ & $2.50 \pm 0.90$ & $1.27,0.29$ \\
\hline Fried chicken & $2.47 \pm 0.83$ & $2.18 \pm 1.1$ & $1.36 \pm 0.82$ & $8.3,0.000$ \\
\hline Remove skin from chicken & $2.47 \pm 1.46$ & $3.14 \pm 1.23$ & $3.21 \pm 1.08$ & $2.06,0.13$ \\
\hline
\end{tabular}

Data expressed as means \pm SD. Differences were calculated using ANOVA 
Table 3 Differences between Food Security Groups in relation to Study Variables using non-parametric test

\begin{tabular}{|c|c|c|c|}
\hline Variable & $\begin{array}{l}\text { Food secure } \\
N=84\end{array}$ & $\begin{array}{l}\text { Food Insecure } \\
N=11\end{array}$ & Nonparametric, p-value \\
\hline Age (y) & 19(32) & $20(29)$ & 0.18 \\
\hline $\mathrm{BMI}\left(\mathrm{Kg} / \mathrm{m}^{2}\right)$ & $21.6(16.9)$ & $22.7(13.5)$ & 0.56 \\
\hline Consumption of low-fat/low-calorie foods & $2(4)$ & $2(4)$ & 0.52 \\
\hline Eat lower fat lunch meats & 2(4) & $1(4)$ & 0.22 \\
\hline Drink skim or $1 \%$ milk & $2(5)$ & $1(5)$ & 0.65 \\
\hline Low fat cheese & $1(4)$ & $1(4)$ & 0.77 \\
\hline Frozen Yogurt & $1(5)$ & 2(5) & 0.11 \\
\hline Use low calorie dressing & $1(4)$ & $1(4)$ & 0.77 \\
\hline Eat fried Potatoes & $3(4)$ & $2(4)$ & 0.08 \\
\hline Frying veggi & $2(5)$ & 2(5) & 0.99 \\
\hline Adding cheese and mayonise & $2(5)$ & 3(5) & 0.03 \\
\hline Eat butter, bread, cake & $1(5)$ & 2(5) & 0.24 \\
\hline Avoid extra fat & $2(4)$ & $2(4)$ & 0.1 \\
\hline Eat Fried chicken & $2(4)$ & $2(4)$ & 0.32 \\
\hline Remove skin & $4(4)$ & $2(4)$ & 0.08 \\
\hline
\end{tabular}

Data is expressed as median (range). Differences between means were Calculated using non-parametric test

This study indicates that food insecurity was not an issue in the studied group of mostly young Palestinians Participants who had access to internet participated in the study so it is expected that food security was uncommon. Previous studies on food security in Palestinian society indicated that prevalence of severe food insecurity $24.6 \%$. Food insecurity was related to poverty, unemployment, low education and having more than seven members in the family [32]. We did not find any common poor dietary habit among the 11 participants who reported some form of food insecurity, neither had we found differences in BMI category or food literacy.

We studied the relationship between BMI category and food habits and food literacy. Obesity and being underweight were not related to food literacy, whereas obese adults were more likely to practice healthier habits

Table 4 Differences between BMI categories in relation to Diet Behavior Variables by ANOVA test

\begin{tabular}{|c|c|c|c|c|}
\hline Variable & Underweight $(\mathrm{N}=11)$ & Normal $(\mathrm{N}=66)$ & Overweight and Obese $(\mathrm{N}=21)$ & $\mathrm{F}, p$-value \\
\hline Age (y) & $19.0 \pm 1.2$ & $21.0 \pm 6.2$ & $30.5 \pm 13.4$ & $12.3, p<0.0001$ \\
\hline $\mathrm{BMI}\left(\mathrm{Kg} / \mathrm{m}^{2}\right)$ & $17.6 \pm 0.7$ & $21.3 \pm 1.82$ & $28.8 \pm 2.30$ & $171.4, p<0.0001$ \\
\hline Low calorie fat & $1.64 \pm 1.21$ & $2.24 \pm 0.84$ & $2.24 \pm 0.70$ & $2.4,0.09$ \\
\hline Low fat meat & $1.55 \pm 1.13$ & $1.89 \pm 1.27$ & $2.0 \pm 1.11$ & $0.50,0.61$ \\
\hline Low fat milk & $2.46 \pm 1.97$ & $1.52 \pm 1.37$ & $2.65 \pm 1.53$ & $5.50,0.006$ \\
\hline Low fat cheese & $1.18 \pm 1.08$ & $1.55 \pm 1.34$ & $1.38 \pm 0.80$ & $0.52,0.6$ \\
\hline Frozen Yogurt & $1.56 \pm 1.33$ & $1.17 \pm 1.54$ & $1.35 \pm 0.93$ & $0.37,0.70$ \\
\hline Low calorie seasoning & $1.18 \pm 1.17$ & $1.39 \pm 1.23$ & $1.38 \pm 1.11$ & $0.15, .86$ \\
\hline Fried Potatoes & $2.0 \pm 1.34$ & $2.59 \pm 1.01$ & $2.42 \pm 1.07$ & $2.39,0.097$ \\
\hline Frying veggi & $2.1 \pm 1.66$ & $2.14 \pm 1.90$ & $1.43 \pm 1.12$ & $1.35,0.27$ \\
\hline Adding cheese and mayonise & $2.20 \pm 2.0$ & $2.06 \pm 1.70$ & $2.10 \pm 1.37$ & $0.03,0.97$ \\
\hline Butter, bread, cake & $1.46 \pm 1.51$ & $1.45 \pm 1.46$ & $1.48 \pm 1.40$ & $0.003,0.99$ \\
\hline Avoid fat & $2.10 \pm 1.22$ & $2.60 \pm 1.14$ & $2.10 \pm 0.89$ & $2.26,0.11$ \\
\hline Fried chicken & $2.36 \pm 1.12$ & $2.03 \pm 1.10$ & $1.67 \pm 0.86$ & $1.73,0.18$ \\
\hline Remove skin & $3.36 \pm 1.12$ & $3.19 \pm 1.18$ & $2.57 \pm 1.36$ & $2.37,0.099$ \\
\hline
\end{tabular}

Data is presented as mean $\pm \mathrm{SD}$, differences were calculated using ANOVA 
Table 5 Multiple Regression Model of the Association between Total literacy score and Study Variables $(n=89)$

\begin{tabular}{llll}
\hline Variable & $\mathbf{B} \pm \mathbf{S E}$ & t-value & $\mathbf{p}$-value \\
\hline Age & $-0.02 \pm 0.02$ & -1.0 & 0.30 \\
Female versus male & $-1.03 \pm 0.94$ & -1.1 & 0.25 \\
Income & & & \\
$\quad 3000$ shikel or less & $-1.8 \pm 1.5$ & -1.2 & 0.23 \\
$\quad$ 3000-6000 shikel & $-0.23 \pm 1.5$ & -0.16 & 0.88 \\
$\quad$ More than 6000 shikel & REF & & \\
Place & & & \\
$\quad$ Village versus city & $-2.5 \pm 0.95$ & -2.5 & 0.035 \\
$\quad$ Refugee camp versus city & $-0.50 \pm 0.9$ & -0.55 & 0.58 \\
Food security score & $-0.15 \pm 0.09$ & -1.8 & 0.079 \\
\hline
\end{tabular}

$B$ is beta coefficient of regression model and SE is standard error. Multiple regression model using total NVS score is dependent outcome in relation to gender, income, total food security score and place of residence,

and underweight group were less likely to practice healthy habits. In a study among university female students obese, overweight and normal weight females did not have significant difference is dietary habits or sleeping duration [33]. Although obese youth may avoid some unhealthy food items, they may have unhealthy practices such as skipping breakfast [34].

\section{Study limitation}

This study was planned and data was collected during corona lockdown. Due to movement restriction we decided to have convenient sample from those who responded to survey online through many websites including university website for students and social media. The response rate was lower than expected, one justification for that could be related to the fact this survey required some calculations and was long, so many individuals were not willing to participate. This could be a bias. Also, we did not collect data on diet intake using any tool such as food frequency questionnaire which could have provided a better view of food habits of study group. Another limitation of this study is its cross sectional design.

\section{Conclusion}

In summary in a group of Palestinian adults mostly in their twenties and females, we found low prevalence of nutrition literacy (29\%) and use of food label (43\%). Many of the study group had unhealthy dietary habits but very few were food insecure. Nutrition literacy was related to diet behavior especially on the willingness of people with higher food literacy to use low fat and low calorie food products and they are also more frequent user of food label. Food insecurity group only had few unhealthy habits, whereas unhealthy dietary habits were common among underweight Palestinians.

\section{Abbreviations}

USDA: United States Department of Agriculture; BMI: Body Mass Index; SFDH KS: short form of diet health and knowledge survey; NHANES: National Health and Nutrition Examination Survey; NVS: Newest Vital Sign

\section{Supplementary Information}

The online version contains supplementary material available at https://doi. org/10.1186/s40795-021-00479-3.

Additional file 1

Acknowledgements

We would like to thank members of the Palestinian society who participated in this study.

Authors' contributions

NN designed the study, collected data, analyzed data and wrote part of the manuscript. M. T obtained IRB approval, revised the manuscript. OI participated in data collection.

\section{Funding}

None.

Availability of data and materials

The datasets generated and/or analyzed during the current study are not publicly available due [being kept confidential for future work] but are available from the corresponding author on reasonable request.

\section{Declarations}

Ethics approval and consent to participate

This study was approved by Najah University IRB board. The goals of the study were discussed in social media platforms and participants were asked to fill online survey.

The research was conducted in accordance with Declaration of Helsinki before conducting the study. Informed consent to participate was obtained from study group who all were $\geq 18 \mathrm{y}$.

\section{Consent for publication}

NA

Competing interests

None.

Received: 3 July 2021 Accepted: 25 October 2021

Published online: 18 November 2021

\section{References}

1. Williams RL, Rollo ME, Schumacher T, Collins CE. Diet quality scores of Australian adults who have completed the healthy eating quiz. Nutrients. 2017;9(8):880. https://doi.org/10.3390/nu9080880.

2. Wang J, Haslam D, Ruan M, Chen F, Du M, Zhang FF. Diet Quality in Association with All-Cause, Cardiovascular, and Cancer Mortality Among US Adults: NHANES 1999-2010 (OR14-04-19). Current Developments in Nutrition. 2019;3(Supplement_1).

3. Lee Y, Mozaffarian D, Sy S, Huang Y, Liu J, Wilde PE, et al. Cost-effectiveness of financial incentives for improving diet and health through Medicare and Medicaid: a microsimulation study. PLoS Med. 2019;16(3):e1002761. https:// doi.org/10.1371/journal.pmed.1002761.

4. Fritsch J, Garces L, Quintero MA, Pignac-Kobinger J, Santander AM, Fernández I, et al. Low-fat, high-fiber diet reduces markers of inflammation and dysbiosis and improves quality of life in patients with ulcerative colitis. Clin Gastroenterol Hepatol. 2021;19(6):1189-1199. e30.

5. Orr CJ, Keyserling TC, Ammerman AS, Berkowitz SA. Diet quality trends among adults with diabetes by socioeconomic status in the U.S.: 19992014. BMC Endocrine Disorders. 2019:19(1):54

6. Brooks N, Begley A. Adolescent food literacy programmes: a review of the literature. Nutrition \& Dietetics. 2014;71(3):158-71. https://doi.org/10.1111/1 747-0080.12096. 
7. Velardo S. The nuances of health literacy, nutrition literacy, and food literacy. Journal of nutrition education and behavior. 2015;47(4):385-389. e1.

8. Taylor MK, Sullivan DK, Ellerbeck EF, Gajewski BJ, Gibbs HD. Nutrition literacy predicts adherence to healthy/unhealthy diet patterns in adults with a nutrition-related chronic condition. Public Health Nutr. 2019;22(12):2157-69. https://doi.org/10.1017/S1368980019001289.

9. Lassetter JH, Clark L, Morgan SE, Brown LB, VanServellen G, Duncan K, et al. Health literacy and obesity among native Hawaiian and Pacific islanders in the United States. Public Health Nurs. 2015;32(1):15-23. https://doi.org/1 $0.1111 /$ phn.12155.

10. Abdi N, Taghdisi MH, Zamani Alavijeh F, Sadeghi R. Nutrition literacy promotion, effective approach for society health promotion. Journal of Health Literacy. 2018;3(3):199-202.

11. Silk KJ, Sherry J, Winn B, Keesecker N, Horodynski MA, Sayir A. Increasing nutrition literacy: testing the effectiveness of print, web site, and game modalities. J Nutr Educ Behav. 2008;40(1):3-10. https://doi.org/10.1016/j. jneb.2007.08.012.

12. Berkman ND, DeWalt DA, Pignone MP, Sheridan SL, Lohr KN, Lux L, et al. Literacy and health outcomes: summary. AHRQ evidence report summaries. 2004.

13. Abu-Saad K, Murad H, Lubin F, Freedman LS, Ziv A, Alpert G, et al. Jews and Arabs in the same region in Israel exhibit major differences in dietary patterns. J Nutr. 2012;142(12):2175-81. https://doi.org/10.3945/jn.112.166611.

14. Damiri B, Dudin B, Sharqiah Q, Khlaif H, Bsharat R, Amir M. Prevalence of low high-density lipoproteins (HDL) cholesterol and its related factors in adult Palestinians: a cross-sectional study.

15. Alizadeh S. Limitation of studies on food intake and dietary pattern in Iran and other Middle East countries: lack of alcohol intake assessment. Nutrients. 2017;9(11):1183. https://doi.org/10.3390/nu9111183.

16. Ndahura NB. Nutrition literacy status of adolescent students in Kampala district. Høgskolen i Oslo og Akershus: Uganda; 2012

17. Lo S, Sharif I, Ozuah PO. Health literacy among English-speaking parents in a poor urban setting. J Health Care Poor Underserved. 2006;17(3):504-11. https://doi.org/10.1353/hpu.2006.0109.

18. Weiss BD, Mays MZ, Martz W, Castro KM, DeWalt DA, Pignone MP, et al. Quick assessment of literacy in primary care: the newest vital sign. The Annals of Family Medicine. 2005;3(6):514-22. https://doi.org/10.1370/afm.4 05.

19. York-Crowe EE, White MA, Paeratakul S, Williamson DA. The diet and health knowledge survey: development of a short interview format. Eat Behav. 2006;7(3):235-42. https://doi.org/10.1016/j.eatbeh.2005.08.010.

20. Speirs KE, Messina LA, Munger AL, Grutzmacher SK. Health literacy and nutrition behaviors among low-income adults. J Health Care Poor Underserved. 2012;23(3):1082-91. https://doi.org/10.1353/hpu.2012.0113.

21. Nasreddine L, Shatila H, Itani L, Hwalla N, Jomaa L, Naja F. A traditional dietary pattern is associated with lower odds of overweight and obesity among preschool children in Lebanon: a cross-sectional study. Eur J Nutr. 2019;58(1):91-102. https://doi.org/10.1007/s00394-017-1574-0.

22. Christian T, Rashad I. Trends in US food prices, 1950-2007. Economics \& Human Biology. 2009;7(1):113-20. https://doi.org/10.1016/j.ehb.2008.10.002

23. Nihal Natour PhD MS. MA-TP, Manwa Al-Ayedi Bsc. Food Label Use and Associated Factors: A cross Sectional Study from Occupied Palestinian Territories; 2021.

24. Yoon HK, Kim GS, Kim S. Parental factors associated with obesity in Korean adolescents. Int J Environ Res Public Health. 2020;17(14):5126. https://doi. org/10.3390/ijerph17145126.

25. Husseini A. Prevalence of diabetes mellitus and impaired glucose tolerance in a rural Palestinian population. EMHJ-Eastern Mediterranean Health Journal, 6 (5-6), 1039-1045, 2000. 2000.

26. Mushi-Brunt C, Haire-Joshu D, Elliott M. Food spending behaviors and perceptions are associated with fruit and vegetable intake among parents and their preadolescent children. J Nutr Educ Behav. 2007;39(1):26-30. https://doi.org/10.1016/j.jneb.2006.06.004.

27. Nihal Natour PhD MS 1 MA-TP. Introducing MyPlate in the curriculum of nutrition teaching for undergraduate medical and health allied professions of Palestinian students. [Article]. In press 2021

28. Ashoori M, Omidvar N, Eini-Zinab H, Shakibazadeh E, Doustmohamadian A, Abdar-Esfahani B, et al. Food and nutrition literacy status and its correlates in Iranian senior high-school students. BMC nutrition. 2021;7(1):1-10. https:// doi.org/10.1186/s40795-021-00426-2.
29. Cesur D, Sümer D. Nutrition literacy status of adults residing in Sivas province and its relationship with quality of life: a cross-sectional study from Turkey. Innovative J Med Health Sci. 2018;8(1):1-9.

30. Aihara $Y$, Minai J. Barriers and catalysts of nutrition literacy among elderly Japanese people. Health Promot Int. 2011;26(4):421-31. https://doi.org/10.1 093/heapro/dar005

31. Mahmudiono T, Nindya TS, Andrias DR, Megatsari H, Rachmah Q, Rosenkranz RR. Comparison of maternal nutrition literacy, dietary diversity, and food security among households with and without double burden of malnutrition in Surabaya. Indonesia Malays J Nutr. 2018;24(3):359-70.

32. Ahmadi $D$, Melgar-Quiñonez $H$. Determinants of food insecurity in occupied Palestinian territory: a cross-sectional survey. Lancet. 2019;393:S4. https://doi. org/10.1016/S0140-6736(19)30590-2.

33. Alhakbany MA, Alzamil HA, Alabdullatif WA, Aldekhyyel SN, Alsuhaibani MN, Al-Hazzaa HM. Lifestyle habits in relation to overweight and obesity among Saudi women attending health science colleges. Journal of epidemiology and global health. 2018;8(1-2):13-9. https://doi.org/10.2991/j.jegh.2018.09.1 00 .

34. Sedibe MH, Pisa PT, Feeley AB, Pedro TM, Kahn K, Norris SA. Dietary habits and eating practices and their association with overweight and obesity in rural and urban black south African adolescents. Nutrients. 2018;10(2):145. https://doi.org/10.3390/nu10020145.

\section{Publisher's Note}

Springer Nature remains neutral with regard to jurisdictional claims in published maps and institutional affiliations.
Ready to submit your research? Choose BMC and benefit from:

- fast, convenient online submission

- thorough peer review by experienced researchers in your field

- rapid publication on acceptance

- support for research data, including large and complex data types

- gold Open Access which fosters wider collaboration and increased citations

- maximum visibility for your research: over $100 \mathrm{M}$ website views per year

At BMC, research is always in progress.

Learn more biomedcentral.com/submission 